\title{
Article \\ Tooth Root Bending Strength of Gears: Dimensional Effect for Small Gears Having a Module below $5 \mathrm{~mm}$
}

\author{
Franco Concli (D)
}

check for updates

Citation: Concli, F. Tooth Root

Bending Strength of Gears:

Dimensional Effect for Small Gears Having a Module below $5 \mathrm{~mm}$. Appl. Sci. 2021, 11, 2416. https://doi.org/ 10.3390/app11052416

Academic Editors: David Barton and Paulo M. S. T. De Castro

Received: 8 February 2021

Accepted: 1 March 2021

Published: 9 March 2021

Publisher's Note: MDPI stays neutral with regard to jurisdictional claims in published maps and institutional affiliations.

Copyright: (C) 2021 by the author. Licensee MDPI, Basel, Switzerland. This article is an open access article distributed under the terms and conditions of the Creative Commons Attribution (CC BY) license (https:/ / creativecommons.org/licenses/by/ $4.0 /)$.
Free University of Bolzano/Bozen, Piazza Università 1, 39100 Bolzano, Italy; franco.concli@unibz.it; Tel.: +39-0471-017748

\begin{abstract}
Downsizing is a more and more widespread trend in many industrial sectors, and, among the others, the automotive industry is pushing the design of its components towards increasingly compact, lightweight, efficient, and reliable solutions. In the past, the drivetrains for automotive were designed and manufactured with gears having modules in the range 3 to 10. In this respect, the main actual European standards for gear design such as ISO 6336:2019 (based on the DIN 3990:1987) are validated in the 3 to $10 \mathrm{~mm}$ range only. Moreover, it is well known that, by increasing the gear size, the gear size factor for tooth bending $Y_{X}$ reduces. However, nowadays the advances in terms of materials and design knowledge have made possible the realization of miniaturized gearboxes with gears having normal modules below $3 \mathrm{~mm}$ with comparable (or better) reliability. In this scenario, understanding how the size affects (positively) the load-carrying capacity for tooth root bending for small modules below $5 \mathrm{~mm}$ is fundamental to maximize the design effectiveness in case of downsizing of the drivetrains. In this paper an experimental study was performed on small gears made of $39 \mathrm{NiCrMo} 3$ having a normal module of $2 \mathrm{~mm}$ to verify the load-carrying capacity for tooth root bending. Based on the experimental evidences and additional data from literature and past studies by the author, an extended formula for the size factor $Y_{X}$ (according to ISO 6336) is proposed.
\end{abstract}

Keywords: gear; tooth root bending; STBF; size factor

\section{Introduction}

In the recent years, downsizing is emerging as a global trend. The miniaturization of the mechanical systems, at least in the automotive sector, is pushed by the more and more stringent environmental restrictions such as the EuroX standards; reducing the size and the weight of the drivetrain has a significant impact on the fuel consumptions and pollutant emissions [1,2]. In other sectors such mechatronics, the compactness and high-power density is fundamental to increase the effectiveness of the robots [3-7]. In these, as in many other applications, the design of gears is moving to smaller and smaller modules, far below $5 \mathrm{~mm}$ [8-10]. Many standards are available for the design of gears such as the European ISO 6336 [11], the German DIN 3990 [12] and the American ANSI/AGMA 2001-D04 [13]. However, the European and German approaches are based on experimental tests performed on gears having a normal module $m_{n}=5 \mathrm{~mm}$. In the past, Steutzger [14] demonstrated that an increased gear size promotes a decrease in the load-carrying capacity for tooth root bending. While this effect is well supported by evidence for modules over $5 \mathrm{~mm}$ [15-18], few data are available below that threshold [19]. If this effect is confirmed, a direct conclusion is that small gears are always oversized when rated with those standards. Therefore, room for improvement exists by applying a specific formulation for the size factor $Y_{X}$ for modules smaller than $5 \mathrm{~mm}$.

The main working principle of the gear standards such ISO 6336 [11] and DIN 3990 [12] relies on the comparison between the occurring stress $\sigma_{F}$ in the component and an allowable (permissible) stress $\sigma_{F P}$. The calculation of the actual stress $\sigma_{F}$ for cylindrical spur gears at the tooth root is based on the Saint-Venant theory: the teeth is idealized as a cantilevered 
beam loaded on the flank with a tangential force $F_{t}$ rotated by an angle $\alpha_{F e n}$ with respect to the tooth axis (Figure 1).

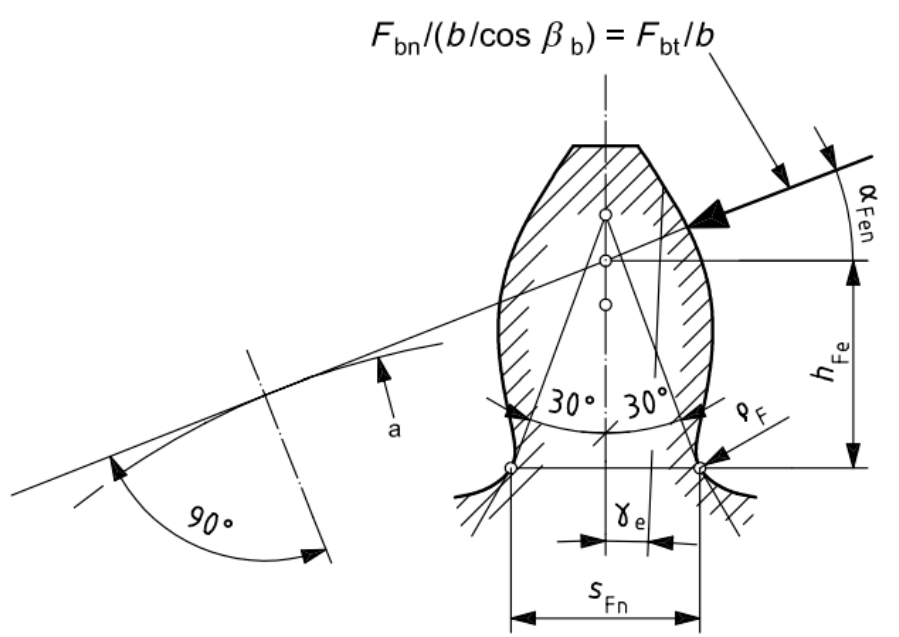

Figure 1. Determination of normal chordal dimensions of tooth root critical section according to ISO 6336-3:2019-Method B.

The determination of the normal chordal dimension $s_{F n}$ of the tooth root critical section and the bending moment $\operatorname{arm} h_{\mathrm{Fe}}$ relevant to load application at the outer point of single pair gear tooth contact according to ISO 6336-Method B is shown in Figure 1.

The occurring stress $\sigma_{F}$ (Equation (1)) results

$$
\sigma_{F}=K_{A} \cdot K_{V} \cdot K_{F \beta} \cdot K_{F \alpha} \cdot \frac{F_{t}}{b \cdot m_{n}} \cdot Y_{F} \cdot Y_{S}
$$

where $Y_{F}$ is defined as in Equation (2)

$$
Y_{F}=\frac{\frac{6 h_{F e}}{m_{n}} \cos \alpha_{F e n}}{\left(\frac{s_{F n}}{m_{n}}\right)^{2} \cos \alpha_{n}}
$$

is the form factor. It takes into account the influence of the tooth form considering that the load is applied at the outer point of single contact. $Y_{S}$ is the stress correction factor and considers the notch effects due to the variation of the section at the tooth root and is used to compensate the errors introduced by the method used to determine the most critical section (oblique lines as prescribed by the ISO 6336-Figure 1) and it is defined as in Equation (3)

$$
Y_{S}=(1.2+0.13 L) \cdot q_{S}^{\frac{1}{1.21+2.3 / L}}
$$

where (Equation (4))

$$
q_{s}=\frac{s_{F n}}{2 \cdot \rho_{F}}
$$

is the notch sensitivity and $L$ is defined as in Equation (5)

$$
L=\frac{s_{F n}}{h_{F e}}
$$

The factor $K_{A}$, called application factor, is used to take into account the effect of external overloading. It depends on the application. The dynamic factor $K_{V}$ considers the internal dynamic loads. The factors $F_{F \beta}$ and $K_{F \alpha}$ are used to model the uneven load distribution in the contacts along the face width and in the transverse direction. These can be caused, for example, by manufacturing errors or deflection of the system under load. 
The occurring stress $\sigma_{F}$ is compared with the permissible bending stress $\sigma_{F P}$ (Equation (6)). The limit value for tooth root stress should preferably be obtained from experimental tests using gears as test pieces. In this way, most of the effects such, for example, the one of fillet at the tooth roots, are automatically included in the results. According to the ISO 6336-Method B, the permissible bending stress $\sigma_{F P}$ can be calculated starting from the nominal stress $\sigma_{\text {Flim }}$ which represent the bending stress limit relevant to the influences of the material, the heat treatment, and the surface roughness of the test gear root fillets.

$$
\sigma_{F P}=\sigma_{F l i m} \cdot Y_{S T} \cdot Y_{N T} \cdot Y_{\delta r e l T} \cdot Y_{R r e l T} \cdot Y_{X}
$$

$Y_{S T}$ and $Y_{N T}$ are the stress correction factor and the life factor for tooth root stress, respectively, both relevant to the dimensions of the reference test gear. $Y_{\delta \text { relT }}$ is the relative notch sensitivity factor, and $Y_{\text {RrelT }}$ is the relative surface factor. Finally, $Y_{X}$ is the size factor relevant to tooth root, which is used to consider the influence of tooth dimensions on tooth root bending strength. It considers the influence of size on the probable distribution of weak points in the structure of the material, the stress gradients, which, in accordance with strength of materials theory [20,21], decrease with increasing dimensions, the quality of the material as determined by the extent and effectiveness of forging, the presence of defects, etc. [11]. According the standard ISO 6336-Method B, the size factor can be estimated as a function of the material and the normal module according to Table 1.

Table 1. Size factor for different modules and materials.

\begin{tabular}{|c|c|c|c|}
\hline \multicolumn{2}{|c|}{ Material } & $\begin{array}{c}\text { Normal Module, } m_{n}[\mathrm{~mm}] \\
m_{n} \leq 5\end{array}$ & \multirow{2}{*}{$\begin{array}{c}\text { Size Factor, } Y_{X}[-] \\
Y_{X}=1.0 \\
Y_{X}=1.03-0.006 \cdot m_{n} \\
Y_{X}=0.85\end{array}$} \\
\hline $\begin{array}{c}\text { St, V, } \\
\text { GGG (perl., bai.), } \\
\text { GTS (perl.), }\end{array}$ & \multirow{3}{*}{ For $3 \times 10^{6}$ cycles } & $\begin{array}{c}m_{n} \leq 5 \\
5 \leq m_{n}<30 \\
30 \leq m_{n}\end{array}$ & \\
\hline $\begin{array}{l}\text { Eh, IF (root), } \\
\text { NT, NV }\end{array}$ & & $\begin{array}{c}m_{n} \leq 5 \\
5 \leq m_{n}<25 \\
25 \leq m_{n}\end{array}$ & $\begin{aligned} & Y_{X}=1.0 \\
Y_{X}= & 1.05-0.01 \cdot m_{n} \\
& Y_{X}=0.8\end{aligned}$ \\
\hline GG, GGG (ferr.) & & $\begin{array}{c}m_{n} \leq 5 \\
5 \leq m_{n}<25 \\
25 \leq m_{n}\end{array}$ & $\begin{array}{c}Y_{X}=1.0 \\
Y_{X}= \\
1.075-0.015 \cdot m_{n} \\
Y_{X}=0.7\end{array}$ \\
\hline All material & r static stress & - & $Y_{X}=1.0$ \\
\hline
\end{tabular}

It can be appreciated that, independently from the material considered, the size factor is always equal to 1.0 for gears having a module below $5 \mathrm{~mm}$. Dobler et al. [19] performed systematic tests on small size gears made of $16 \mathrm{MnCr} 5$ having a normal module $m_{n}=0.45 \div 0.6 \mathrm{~mm}$. The gears were hobbed and case-carburized to $700-750 \mathrm{HV}$ of surface hardness. The treatment had a depth $(550 \mathrm{HV})$ of 0.1 to $0.2 \mathrm{~mm}$. Finally, the gears were grinded to a quality $<5$ according to DIN 3962 [22]. All the tests were performed on a small-gear back-to-back rig having a reduction ratio of 57-58. Based on 20 tests [23-26], a modified expression for the gear size factor $Y_{X}$ for steels was proposed (Equation (7)).

$$
Y_{X_{\text {Dobler }}}=1-0.45 \cdot \log \left(\frac{m_{n}}{5}\right) \pm 0.075
$$

These formulation fits the data according to FVA 162/I [26], FVA 271 [25], FVA 410/I [23], and Jeong [24] with a coefficient of determination $R^{2}=0.9339$.

It is interesting to notice that, according to the model proposed by Dobler et al., based on several results available in the literature, for modules over $5 \mathrm{~mm}$ the load-carrying capacity for tooth root bending decreases. The actual formulation of the standards (ISO 6336 and DIN 3990), in turn, does not fit the experimental observed behavior $\left(R^{2}=-0.2203\right.$ referred to the Eh curve). 


\section{Material and Methods: Fine-Module Gears}

In order to evaluate the influence of the gear size on the load-carrying capacity for tooth bending, Single Tooth Bending Fatigue (STBF) [27] tests were performed on a gear having normal module $m_{n}=2 \mathrm{~mm}$ made of $39 \mathrm{NiCrMo3}$. The tests were performed on a STEPlab UD04 electromechanical monoaxial pulsator capable to apply up to $5 \mathrm{kN}$. To perform STBF tests, a special apparatus consisting of 2 anvils, a supporting fork, and a centering pin was developed (Figure 2). The STBF tests take advantage of the Wildhaber distance W5 [28] to simultaneously load two teeth, ensuring that the contact forces are on one hand parallel and coaxial among them, on the other hand perpendicular to the teeth flanks. In this manner, during the test the friction between anvils and gear flanks is enough to keep the gear sample in position without the need of external supports. The fork and the centering pin are required during the mounting stage only to ensure that the contact points between gear flanks and anvils are in the correct positions. On the other side of the coin, with this configuration it is not possible to perform tests keeping the stress ratio $R=0$ as in engaging gears. A minimum compressive load should be always present to ensure that the gear remains in the correct position [29]. Based on literature [30-34], a value of $R=0.1$ is sufficient to ensure that no undesired movement will take place.
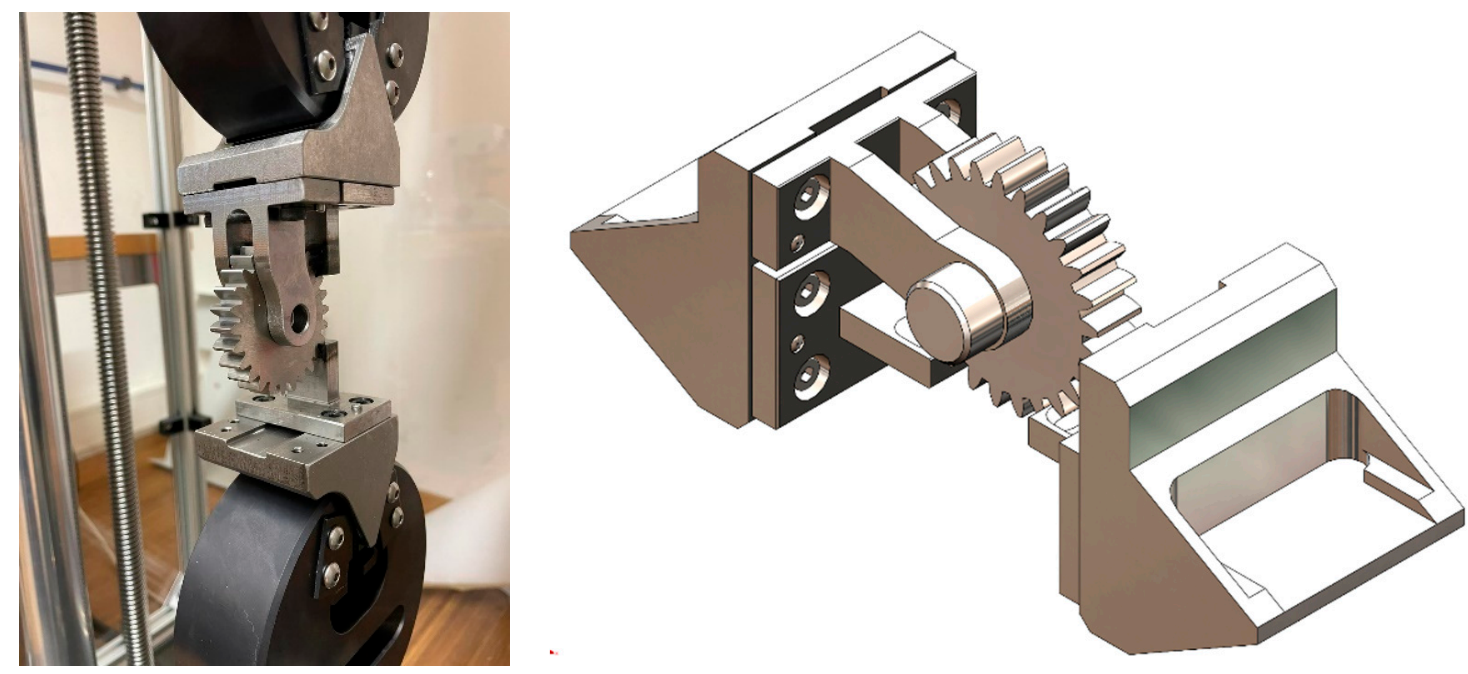

Figure 2. Scheme of the testing apparatus.

Table 2 summarizes the geometrical properties of the gear samples. The quality of the gear is 5 according to DIN 3962 [22] (EN).

Table 2. Gear data-2 mm-module gear.

\begin{tabular}{cccccc}
\hline $\boldsymbol{m}_{\boldsymbol{n}}[\mathrm{mm}]$ & 2 & $\boldsymbol{d}_{\boldsymbol{e n}}[\mathrm{mm}]$ & 52.000 & $\boldsymbol{x}[-]$ & 0.300 \\
$\boldsymbol{\alpha}_{\boldsymbol{n}}\left[^{\circ}\right]$ & 20 & $\boldsymbol{d}_{\boldsymbol{b}}[\mathrm{mm}]$ & 48.846 & $\boldsymbol{h}_{f \boldsymbol{P}^{*}}[\mathrm{~mm}]$ & 1.250 \\
$\boldsymbol{z}_{\boldsymbol{n}}[-]$ & 26 & $\boldsymbol{d}_{\boldsymbol{a}}[\mathrm{mm}]$ & 57.200 & $\rho_{f \boldsymbol{P}^{*}}[\mathrm{~mm}]$ & 0.380 \\
$\boldsymbol{b}[\mathrm{mm}]$ & 10 & $\boldsymbol{d}_{\boldsymbol{f}}[\mathrm{mm}]$ & 47.960 & $\boldsymbol{h}_{\boldsymbol{a} \boldsymbol{P}^{*}}[\mathrm{~mm}]$ & 1.000 \\
\hline
\end{tabular}

The tests were performed according to the stair-case approach [35]. If a test at a certain force level $F_{i}$ ended with a failure, the force for the successive test was decreased by $\Delta F$. If the test ended with a Run-Out (the sample withstand $5 \mathrm{M}$ cycles) the force was increased by $\Delta F$. The force interval $\Delta F$ was set to $100 \mathrm{~N}$.

The Up-and-Down Method for Small Samples with Two Specimens "in Series" according to Little [36] was used to post-process the results. It is based on the original work of Dixon [37] which allows the estimation of the fatigue limit starting from a small number of samples thanks to the adoption of statistics. This work was successively developed by 
Little in order to take into account the effect of samples mounted in series. An STBF test is a typical example of this configuration.

Fatigue failure occurs generally before about $1 \mathrm{M}$ cycles having all the same amplitude. However, it is common testing practice to select an arbitrary test duration (Run-Out). In this manner, a substantial portion of the testing time is spent where failure is unlikely, but the run-out condition has not yet been reached. Interrupting individual tests when the first specimen fails (one of the 2 tested gear teeth) means off course saving time, but also losing information regarding the subsequent response (if any) of the second tooth. The method proposed by Little takes into account this effect statistically.

The fatigue limit $F_{F P_{S T B F 5 \%}}$ is estimated as the sum of the first meaningful load level $F_{1}$ (Equation (8)).

$$
F_{F P_{S T B F 50 \%}}=F_{1}+k \cdot \Delta F
$$

where $k$ a statistical parameter depending on the Failure (F) - Run-Out (RO) sequence.

\section{Results}

Table 3 shows the summary of the test results performed on the fine-module gears.

Table 3. Test results relative to the $2 \mathrm{~mm}$-module gear.

\begin{tabular}{ccccc}
\hline Test ID & $\boldsymbol{F}_{\boldsymbol{m a x}}[\boldsymbol{N}]$ & $\boldsymbol{F}_{\boldsymbol{m i n}}[\boldsymbol{N}]$ & $\boldsymbol{N}[-]$ & Status \\
\hline 1 & -365 & -3650 & $5.00 \times 10^{6}$ & $\mathrm{RO}$ \\
2 & -375 & -3750 & $5.00 \times 10^{6}$ & $\mathrm{RO}$ \\
3 & -385 & -3850 & $5.00 \times 10^{6}$ & $\mathrm{RO}$ \\
4 & -395 & -3950 & $5.00 \times 10^{6}$ & $\mathrm{RO}$ \\
5 & -405 & -4050 & $4.17 \times 10^{5}$ & $\mathrm{~F}$ \\
6 & -395 & -3950 & $3.33 \times 10^{6}$ & $\mathrm{~F}$ \\
\hline
\end{tabular}

Being the results of the testing campaign in the order RO-RO-RO-RO-F-F, the value of $k=3.56$ leads to a permissible force $F_{F P_{S T B F 50 \%}}=4006 \mathrm{~N}$. This value $(4006 \mathrm{~N})$ represents the fatigue limit for a probability of $50 \%$ of failure. Therefore, the result was decreased by 2.33.s, where $s$ represents the variance that, according to the Up-and-Down Method for Small Samples with Two Specimens "in Series" according to Little, is equal to the force interval $\Delta F$. This leads to a fatigue limit with a failure probability of $1 \% F_{F P_{S T B F 1 \%}}=3773 \mathrm{~N}$.

The result was multiplied by a factor 0.9 to consider the fact that the tests were performed on a pulsator without meshing [38,39].

This force can be converted into a permissible stress $\sigma_{F P}$, equal to the actual one $\sigma_{F}$, using the abovementioned formulas (ISO 6336). For the specific geometry, the form factor $Y_{F}$ and the stress correction factor $Y_{S}$ result, respectively, in 2.0298 and 1.9011. The values of $h_{F e}(3.3159 \mathrm{~mm})$ and $s_{F e}(4.2999 \mathrm{~mm})$ for the calculation of $Y_{F}$ were graphically extracted (Figure 3).
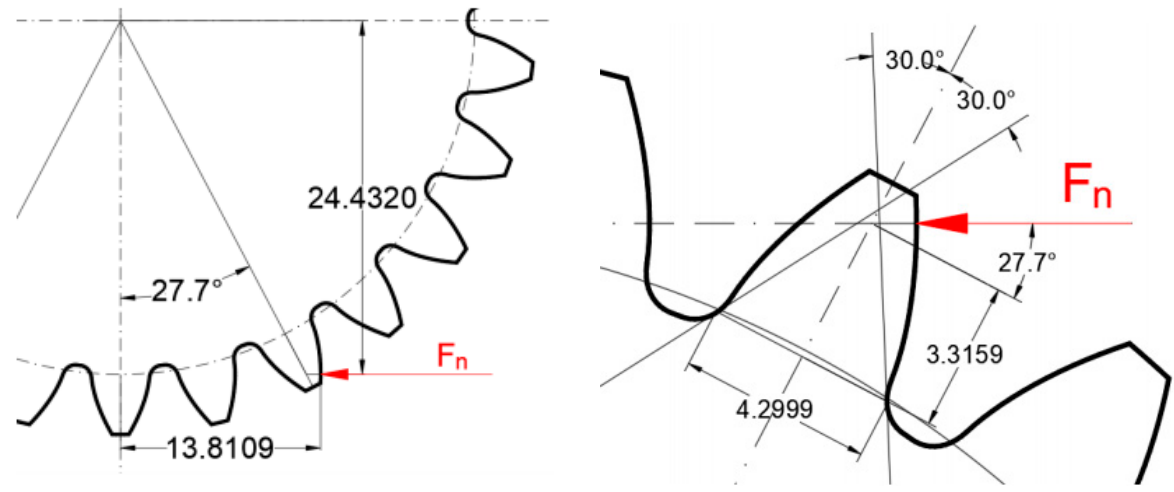

Figure 3. Determination of the most critical section. 
The value of the permissible stress $\sigma_{F P_{2 m m}}$ results $570.34 \mathrm{MPa}$.

According to literature [11], the nominal stress for $39 \mathrm{NiCrMo} 3$ is $\sigma_{\text {Flim }}=280.92 \mathrm{MPa}$. This value was obtained with standard $5 \mathrm{~mm}$ module gears for which the factors $Y_{N T}$, $Y_{\text {drelT }}, Y_{\text {RrelT }}$ as well as the size factor $Y_{X}$ result equal to one. $Y_{S T}$ is instead equal to 2 . Therefore, the corresponding permissible stress $\sigma_{F P_{5 m m}}$ results $561.84 \mathrm{MPa}$.

For the actual gear having normal module equal to $2 \mathrm{~mm}, Y_{N T}$ is also equal to one. $Y_{\text {RrelT }}$ is the relative surface factor. It is function of the roughness $R_{Z}$. For the tested gears, the roughness $R_{a}$ of the fillet was measured to be $6.3 \mu \mathrm{m}$. This value was converted into $R_{Z}$ using the DIN 4778 [40] resulting in $38.3 \mu \mathrm{m}$. For this value of roughness, the ISO 6336 proposes a relative surface factor $Y_{\text {RrelT }}=0.9458$. $Y_{\text {drel } T}$ is the notch sensitivity factor (Equation (9)).

$$
Y_{\delta r e l T}=\frac{1+\sqrt{\rho^{\prime} \chi^{*}}}{1+\sqrt{\rho^{\prime} \chi_{T}^{*}}}
$$

where $\rho^{\prime}$ is the slip player thickness, that for the present material is equal to $0.083, \chi^{*}$ is the relative stress gradient of the actual gear and $\chi_{T}^{*}$ is the corresponding value for reference gears where the notch parameter $q_{s T}=1.0$. For the $2 \mathrm{~mm}$ module gear, the notch parameter $q_{s}$ according to Equation (10)

$$
q_{s}=\frac{s_{F n}}{2 \cdot \rho_{F}}
$$

results in $q_{s}=2.6659 . Y_{\delta \text { relT }}=0.9458$.

The direct comparison of the two values of permissible stress leads to the estimation of the size factor for the $2 \mathrm{~mm}$ normal module gear. It results $Y_{X}=1.1327$. This value aligned with the findings of Dobler et al. ( $-3.9 \%$ as shown in Figure 4$)$ and significantly above the value proposed by the ISO 6336 and the DIN 3990 standards (+13.3\%).

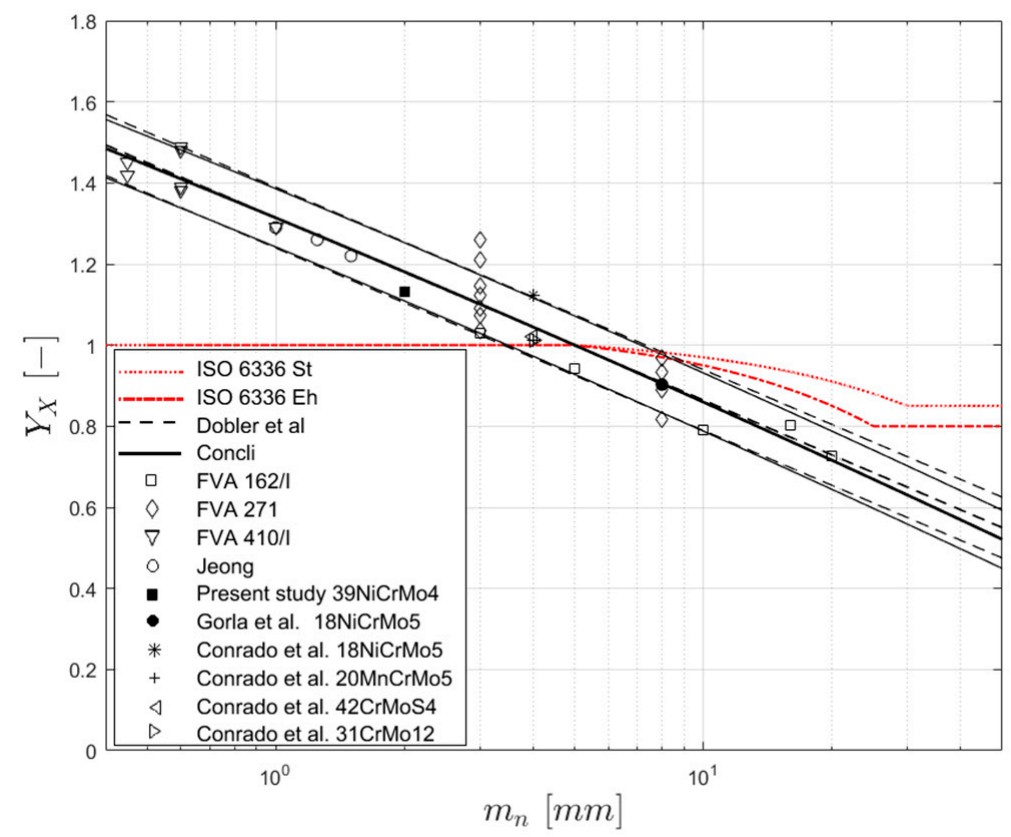

Figure 4. Gear size factor vs. module.

\section{Discussion}

The result of the testing campaign on the $2 \mathrm{~mm}$-module gears has confirmed what highlighted by Dobler et al., that for normal modules below $5 \mathrm{~mm}$ the ISO 6336 approach underestimate the load carrying capacity of gears. To have a further confirmation of this phenomenon, already published data by the research group of the author were elaborated.

Specifically, tests on $8 \mathrm{~mm}$-module gears according to Gorla et al. [32] and on $4 \mathrm{~mm}$ module gears according to Conrado et al. [41] were used. In both cases, the tests were 
performed in order to compare different materials or investigate the effect of heat- or mechanical-treatments. In both cases the results were compared to a reference case and only the relative load carrying capacity increment was considered.

For the materials tested by Gorla et al. and by Conrado et al. results in terms of tooth root bending resistance obtained on standard $5 \mathrm{~mm}$-module gears are also available in literature [11]. A direct comparison of the fatigue limits obtained by Gorla et al. and by Conrado et al. with their counterparts from literature, allow the calibration of the gear size coefficient $Y_{X}$ also for these configurations characterized by different modules and materials.

\subsection{Additional Data for the Calibration of a New Formulation for $Y_{X}: 8 \mathrm{~mm}$ Module Gears According to Gorla et al.}

To better calibrate a new formulation for $Y_{X}$, valid not only for modules below $5 \mathrm{~mm}$ but in the whole range, additional data obtained by the author in a previous research were considered. The tests were performed in the framework of the project XL-Gear funded by Regione Lomabardia [32]. While the aim was to identify innovative solutions capable to improve large gears manufacturing as well as durability and strength, a standard case hardening steel (18NiCrMo5) with a standard manufacturing cycle has been adopted as a base-line.

The geometrical parameters of the gear are shown in Table 4 . The surface roughness was $\mathrm{Ra}=1.6 \mu \mathrm{m}$.

Table 4. Gear data relative to the $8 \mathrm{~mm}$-module gear.

\begin{tabular}{cccccc}
\hline$m_{n}[\mathrm{~mm}]$ & 8 & $\boldsymbol{d}_{\boldsymbol{e n}}[\mathrm{mm}]$ & 256.000 & $x[-]$ & 0.223 \\
$\boldsymbol{\alpha}_{n}\left[^{\circ}\right]$ & 20 & $\boldsymbol{d}_{\boldsymbol{b}}[\mathrm{mm}]$ & 240.561 & $\boldsymbol{h}_{f \boldsymbol{P}^{*}}[\mathrm{~mm}]$ & 1.250 \\
$\boldsymbol{z}_{\boldsymbol{n}}[-]$ & 32 & $\boldsymbol{d}_{\boldsymbol{a}}[\mathrm{mm}]$ & 275.5570 & $\boldsymbol{\rho}_{f \boldsymbol{P}^{*}}[\mathrm{~mm}]$ & 0.300 \\
$\boldsymbol{b}[\mathrm{mm}]$ & 20 & $\boldsymbol{d}_{f}[\mathrm{~mm}]$ & 239.557 & $\boldsymbol{h}_{\boldsymbol{a} \boldsymbol{P}^{*}}[\mathrm{~mm}]$ & 1.000 \\
\hline
\end{tabular}

Tests were performed on a $60 \mathrm{kN}$ electromechanical Schenk pulsator similarly to the tests performed on the small gear. Tests were performed with the short staircase method and post processed with the Dixon [37] approach. The stress that leads to a $50 \%$ failure probability results $\sigma_{F P_{S T B F 50 \%}}=1007 \mathrm{MPa}$. This value was converted into the $1 \%$ failure probability $\sigma_{F P_{S T B F 1 \%}}=\sigma_{F P_{S T B F 50 \%}}-2.33 \cdot s=916 \mathrm{~N}$, where $s$ is the variance $(39.6 \mathrm{MPa})$. This value was then multiplied by the a 0.9 factor to consider the fact that the tests were performed on a pulsator without meshing [38,39], resulting in $\sigma_{F P_{50 \%}}=824 \mathrm{MPa}$..

According to literature [11], the nominal stress for $18 \mathrm{NiCrMo5}$ is $\sigma_{\text {Flim }}=430 \mathrm{MPa}$. This value was obtained with standard $5 \mathrm{~mm}$ module gears for which the factors $Y_{N T}$, $Y_{\delta \text { relT }}, Y_{\text {RrelT }}$, as well as the size factor $Y_{X}$ result equal to one. $Y_{S T}$ is instead equal to 2 . Therefore, the corresponding permissible stress $\sigma_{F P_{5 \mathrm{~mm}}}$ results $860 \mathrm{MPa}$.

For the $8 \mathrm{~mm}$ gear, $Y_{N T}$ is equal to one. $Y_{\text {RrelT }}$, the relative surface factor results $Y_{\text {RrelT }}=0.9964$ while the notch sensitivity factor $Y_{\delta \text { relT }}=0.9449$. Therefore, the size factor $Y_{X}$ results $Y_{X}=0.9027$. This results highlight that also for modules bigger than $5 \mathrm{~mm}$, the ISO 6336 and the DIN 3990 standards (considering the Eh curve for case hardening steels) did not well predict the experimental evidences, and overestimate the value of the size factor by $+10.4 \%$.

\subsection{Additional Data for the Calibration of a New Formulation for $Y_{\mathrm{X}}$ : 4 mm Module Gears According to Conrado et al.}

Additional data were extracted from the publication of Conrado et al. [41] performed on the same electromechanical $65 \mathrm{kN}$ Schenk pulsator used by Gorla et al. [32]. The tested gears have a normal module $m_{n}=4 \mathrm{~mm}$. The other geometrical parameters are shown in Table 5. The surface roughness was $\mathrm{Ra}=3.2 \mu \mathrm{m}$. 
Table 5. Gear data relative to the $4 \mathrm{~mm}$-module gear.

\begin{tabular}{cccccc}
\hline$m_{n}[\mathrm{~mm}]$ & 4 & $\boldsymbol{d}_{\boldsymbol{e}}[\mathrm{mm}]$ & 256.000 & $\boldsymbol{x}[-]$ & 0.000 \\
$\boldsymbol{\alpha}_{\boldsymbol{n}}\left[^{\circ}\right]$ & 20 & $\boldsymbol{d}_{\boldsymbol{b}}[\mathrm{mm}]$ & 105.250 & $\boldsymbol{h}_{f \boldsymbol{P}^{*}}[\mathrm{~mm}]$ & 1.250 \\
$\boldsymbol{z}_{\boldsymbol{n}}[-]$ & 28 & $\boldsymbol{d}_{\boldsymbol{a}}[\mathrm{mm}]$ & 120.000 & $\boldsymbol{\rho}_{f \boldsymbol{P}^{*}}[\mathrm{~mm}]$ & 0.300 \\
$\boldsymbol{b}[\mathrm{mm}]$ & 30 & $\boldsymbol{d}_{f}[\mathrm{~mm}]$ & 101.910 & $\boldsymbol{h}_{\boldsymbol{a} \boldsymbol{P}^{*}}[\mathrm{~mm}]$ & 1.000 \\
\hline
\end{tabular}

Test gears were manufactured from four different base materials: two carburizing, one nitriding, and one through-hardening steel grades, commonly used as materials for surface hardened gears: $18 \mathrm{NiCrMo5}, 20 \mathrm{MnCr} 5,42 \mathrm{CrMoS} 4$, and $31 \mathrm{CrMo} 12$. The experiments were conducted on 15 samples for each material following the staircase procedure. The results of the testing campaign are shown in Table 6.

Table 6. Test results relative to the $4 \mathrm{~mm}$-module gear.

\begin{tabular}{cccccc}
\hline Material & $\sigma_{F P_{\text {STBF5\% }}}[\mathrm{MPa}]$ & $s[\mathrm{MPa}]$ & $\sigma_{F P_{\text {STB } 1 \%}}[\mathrm{MPa}]$ & $\sigma_{F P_{1 \%}}[\mathrm{MPa}]$ & $\boldsymbol{Y}_{\boldsymbol{X}}$ \\
\hline 18NiCrMo5 & 1185 & 47.9 & 1073 & 966 & 1.1233 \\
20MnCr5 & 1084 & 33.2 & 1007 & 869 & 1.0110 \\
42CrMoS4 & 1011 & 15.4 & 975 & 877 & 1.0205 \\
31CrMo12 & 1036 & 29.4 & 968 & 870 & 1.0126 \\
\hline
\end{tabular}

By comparing these values with the permissible stress values from literature, it is possible to determine the size factors that results: $Y_{X}=1.1233,1.0110,1.0205$, and 1.0126 , respectively.

\section{Proposal of a New Formulation for $Y_{X}$}

Based on the results of the present study, and on the data available in literature, a new formulation for $Y_{X}$ is proposed. Differently from the model according to Dobler et al. which uses a linear interpolating function, a 2nd order polynomial function was used to interpolate the data.

$$
Y_{X}=1-0.0176\left(\log _{10}\left(\frac{m_{n}}{m_{n T}}\right)\right)^{2}-0.4613 \cdot \log _{10}\left(\frac{m_{n}}{m_{n T}}\right)
$$

The coefficient of determination $R^{2}$ results 0.9296 . On the same set of data, the model of Dobler et al. shows a coefficient of determination of 0.9292 .

Moreover, while the $90 \%$ reliability interval according to the model proposed by Dobler et al. lies within \pm 0.0750 around the mean value, in the present model, thanks to a lower standard deviation, the offset is \pm 0.0718 .

While on the present set of data the adoption of a 2nd order polynomial function does not introduce big benefits, for high modules the difference becomes evident (Figure 4). Only further tests or availability of data for big modules could really indicate which of the two models better describe the real (physical) trend of $Y_{X}$ vs. $m_{n}$.

\section{Conclusions}

On the one hand, miniaturization is an actual trend and, therefore, new designs will adopt more and more small gears. On the other hand, the actual standards did not properly include the effect of the size of the gears on the allowable stresses for modules different from $5 \mathrm{~mm}$. Therefore, there is the need for new extended factors. Dobler et al. proposed a new formulation for the size factor $Y_{X}$ based on experiments performed on gear samples made of $16 \mathrm{MnCr} 5$ and having modules between 0.45 and $20 \mathrm{~mm}$. The experimental evidence shows that for small gears having a normal module below $5 \mathrm{~mm}$, the allowable stresses results significantly above those for standard reference gear. The results of this work are aligned with the findings of Dobler et al., confirming the increased load carrying capacity of small gears. 
In this study the reference stress $\sigma_{F_{l i m}}$ for gears made by $39 \mathrm{NiCrMo} 3$ having a normal module $m_{n}=2 \mathrm{~mm}$ was obtained via STBF tests. Tests were conducted using the short staircase approach and the results statistically postprocessed with the up-and-down method for small samples with two specimens "in series" according to Little. The ISO 6336 standard was applied to convert the applied forces into stresses. The obtained value of reference stress was compared with the one available in literature for $39 \mathrm{NiCrMo3}$. This comparison has led to the calibration of the size factor $Y_{X}$ according to ISO 6336 for a normal module $m_{n}=2 \mathrm{~mm}$ resulting in $Y_{X}=1.1327$. This value is significantly above the value suggested by the standard $\left(Y_{X}=1\right)$ and aligned with the model proposed by Dobler et al.

In addition to that, in order to have a more reliable data set, starting from data published by author's research group in the past and the comparison of those data with literature data available for the same materials and obtained on $5 \mathrm{~mm}$-module gears, additional values for the gear size factor for $4 \mathrm{~mm}$ - and $8 \mathrm{~mm}$-module gears were derived.

Finally, based on the actual data, data on literature, results published by the author in the past, and other data from collaborators, an alternative formulation for the size factor $Y_{X}$ was proposed. This formulation shows a slightly higher coefficient of determination $R^{2}$ with respect to the model proposed by Dobler et al. and significantly higher than the one proposed by the ISO 6336 and DIN 3990 standards. However, while both the actual model and the one according to Dobler et al. show similar trends in the 2-20 mm module range, for higher values they differ significantly. In order to clarify which one is more suitable, additional tests are planned on big-module gears.

Author Contributions: F.C. followed the development of the rig, performed the tests, post-processed the results and wrote the paper. The author has read and agreed to the published version of the manuscript.

Funding: This work was supported by the Open Access Publishing Fund of the Free University of Bozen-Bolzano.

Institutional Review Board Statement: Not applicable.

Data Availability Statement: The datasets used and analyzed during the current study are available from the corresponding author on reasonable request.

Conflicts of Interest: The authors declare that they have no competing interests.

$\begin{array}{ll}\text { Abbreviations } \\ \text { F } & \text { Failure } \\ \text { RO } & \text { Run-Out } \\ \text { STBF } & \text { Single Tooth Bending Fatigue }\end{array}$

\section{References}

1. Punov, P.; Evtimov, T.; Chiriac, R.; Clenci, A.; Danel, Q.; Descombes, G. Progress in high performances, low emissions, and exergy recovery in internal combustion engines. Green Energy Technol. 2018, 1, 995-1016.

2. Punov, P.; Evtimov, T.; Chiriac, R.; Clenci, A.; Danel, Q.; Descombes, G. Progress in high performance, low emissions, and exergy recovery in internal combustion engines. Int. J. Energy Res. 2017, 41, 1229-1241. [CrossRef]

3. Dong, X.; Fu, M.; Li, J.; Li, J.; Zhao, Y. Optimization design of the wire repair tool for the maintenance robot with charged used in substation. IOP Conf. Ser. 2019, 563, 042033. [CrossRef]

4. Groenhuis, V.; Siepel, F.J.; Stramigioli, S. Miniaturization of MR Safe Pneumatic Rotational Stepper Motors. In Proceedings of the IEEE International Conference on Intelligent Robots and Systems (IROS), Macau, China, 3-8 November 2019; pp. 7150-7156.

5. Hemmi, M.; Morita, R.; Hirota, Y.; Inoue, K.; Nabae, H.; Endo, G.; Suzumori, K. Development of Hydraulic Tough Motors with High Power Density and their Application to a 7-axis Robotic Arm. In Proceedings of the 2019 IEEE/SICE International Symposium on System Integration, SII 2019, Paris, France, 14-16 January 2019; pp. 264-269.

6. Yang, X.; Xue, Y.; Zhou, J.; Concli, F. Stress distribution and fluctuation cycle on the rack face of the rock cutting tool. Shock Vib. 2019, 2019, 6830519. [CrossRef]

7. Wan, T. Design and Analysis of a Snake-like Surgical Robot with Continuum Joints. In Proceedings of the ICARM 2020-2020 5th IEEE International Conference on Advanced Robotics and Mechatronics, Shenzen, China, 18-21 December 2020; pp. 178-183.

8. Braykoff, C. Tragfähigkeit kleinmoduliger Zahnräder. Ph.D. Thesis, Technische Universität München, München, Germany, 2007. 
9. Concli, F. Low-loss gears precision planetary gearboxes: Reduction of the load dependent power losses and efficiency estimation through a hybrid analytical-numerical optimization tool [Hochleistungs- und Präzisions-Planetengetriebe: Effizienzschätzung und Reduzierun. Forsch. im Ingenieurwesen/Eng. Res. 2017, 81, 395-407. [CrossRef]

10. Hinterstoißer, M.; Sedlmair, M.; Lohner, T.; Stahl, K. Minimizing Load-dependent Gear Losses. Tribol. und Schmierungstechnik. 2019, 66, 15-25.

11. International Organization for Standardization. ISO 6336. Calculation of Load Capacity of Spur and Helical Gears; International Organization for Standardization: Geneva, Switzerland, 2006.

12. German Institute for Standardisation. DIN 3990. Calculation of Load Capacity of Cylindrical Gears-Introduction and General Influence Factors; German Institute for Standardisation: Berlin, Germany, 1987.

13. American National Standards Institute; American Gear Manufacturers Association. ANSI/AGMA 2001. Fundamental Rating Factors and Calculation Methods for Involute Spur and Helical Gear Teeth; American National Standards Institute; American Gear Manufacturers Association: Alexandria, VA, USA, 2004.

14. Steutzger, M. Großeneinfluss auf die Zahnfussfestigkeit; FVA: Frankfurt, Germany, 1997.

15. Hertter, T. Rechnerischer Festigkeitsnachweis der Ermüdungstragfähigkeit vergüteter und einsatzgehärteter Stirnräder. Ph.D. Thesis, Technische Universitaet Muenchen, München, Germany, 2003.

16. Hoehn, B.-R.; Oster, P.; Braykoff, C. Size and material influence on the tooth root, pitting, scuffing and wear load carrying capacity of fine module gears. In Proceedings of the VDI International Conference on Gears, Munich, Germany, 4-6 October 2010; pp. $1295-1307$.

17. Hoehn, B.-R.; Oster, P.; Braykoff, C. Calcolo della capacità di carico degli ingranaggi con modulo piccolo. Organi di Trasm. 2011, $42,104-112$.

18. International Organization for Standardization. ISO 1328. Cylindrical Gears_ISO System of Flank Tolerance Classification; International Organization for Standardization: Geneva, Switzerland, 2013.

19. Dobler, A.; Hergesell, M.; Tobie, T.; Stahl, K. Increased tooth bending strenght and pitting load capacity of fine-module gears. Gear Technol. 2016, 33, 48-53.

20. Davoli, P.; Vergani, L.; Beretta, S. Costruzioni di Macchine I; McGraw-Hill Education: New York, NY, USA, 2017.

21. Issler, L.; Ruoß, H.; Häfele, P. Festigkeitslehre—Grundlagen; Springer: Berlin/Heidelberg, Germany, 2013.

22. German Institute for Standardisation. DIN 3962. Tolerances for Cylindrical Gear Teeth; German Institute for Standardisation: Berlin, Germany, 1978.

23. FVA 410/I, Abschlussbericht 410/I.

24. Jeong, B.; Kato, M.; Katsumi, I.; Takatsu, N. The Bending Strength of Carburized Fine Module Gear Teeth. JSME Int. J. Ser. 3 Vib. Control Eng. Eng. Ind. 1992, 35, 136-141.

25. FVA 271, Abschlussbericht FVA 271.

26. FVA 162/I, Abschlussbericht FVA 162/I.

27. Society of Automotive Engineers. Single Tooth Gear Bending Fatigue Test; Society of Automotive Engineers: Warrendale, PA, USA, 1997.

28. MAAG Gear Company Limited. Maag Gear Book: Calculation and Practice of Gears, Gear 364 Drives Toothed Couplings and Synchronous Clutch Couplings; MAAG Gear Company Limited: Copenhagen, Denmark, 1990.

29. Bonaiti, L.; Concli, F.; Gorla, C.; Rosa, F. Bending fatigue behaviour of 17-4 PH gears produced via selective laser melting. Procedia Struct. Integr. 2018, 24, 764-774. [CrossRef]

30. Gasparini, G.; Mariani, U.; Gorla, C.; Filippini, M.; Rosa, F. Bending 367 Fatigue Tests of Helicopter Case Carburized Gears: Influence of Material, Design 368 and Manufacturing Parameters. In Proceedings of the American Gear Manufacturers Association 369 (AGMA) Fall Technical Meeting, San Antonio, TX, USA, 12-14 October 2008; pp. 131-142.

31. Concli, F. Austempered Ductile Iron (ADI) for gears: Contact and bending fatigue behavior. Procedia Struct. Integr. 2018, 8, 14-23. [CrossRef]

32. Gorla, C.; Rosa, F.; Concli, F.; Albertini, H. Bending fatigue strength of innovative gear materials for wind turbines gearboxes: Effect of surface coatings. In Proceedings of the ASME International Mechanical Engineering Congress and Exposition, (IMECE), Houston, TX, USA, 9-15 November 2012; ASME: New York, NY, USA, 2012; Volume 7, parts A, B, C, D.

33. Gorla, C.; Rosa, F.; Conrado, E.; Concli, F. Bending fatigue strength of case carburized and nitrided gear steels for aeronautical applications. Int. J. Appl. Eng. Res. 2017, 12, 11306-11322.

34. Gorla, C.; Conrado, E.; Rosa, F.; Concli, F. Contact and bending fatigue behaviour of austempered ductile iron gears. Proc. Inst. Mech. Eng. Part C 2018, 232, 998-1008. [CrossRef]

35. Marsalek, P.; Moravec, V. A methodology for gear fatigue tests and their evaluation. MECCA J. Middle Eur. Constr. Des. Cars. 2011, 9 .

36. Little, R.E. The up-and-down method for small samples with two specimens 'in series'. J. Am. Stat. Assoc. 1975, 70, 846-851.

37. Dixon, W.J. The Up-and-Down Method for Small Samples. J. Am. Stat. Assoc. 1965, 60, 967-978. [CrossRef]

38. Mauch, H. Statistische Methoden zur Beurteilung von Bauteillebensdauer und Zuverlässigkeit und Ihre Beispielhafte Anwendung auf Zahnräder; FVA: Frankfurt, Germany, 1997.

39. Rettig, H. Zahnradversuche Auf Verspannungsprfstnden Und Pulsatoren-Ein Numerischer Vergleich Der ZahnfufestigkeitsKennwerte. In Proceedings of the 2nd World Congress on Gearing Paris, Paris, France, 2-5 March 1986. 
40. German Institute for Standardisation. DIN 4778; German Institute for Standardisation: Berlin, Germany, 1990.

41. Conrado, E.; Gorla, C.; Davoli, P.; Boniardi, M. A comparison of bending fatigue strength of carburized and nitrided gears for industrial applications. Eng. Fail. Anal. 2017, 78, 41-54. [CrossRef] 